\title{
ANALYSIS OF MULTI-PIN MODULAR DAUGHTERBOARD-TO-BACKPLANE CONNECTORS AT HIGH BIT RATE SIGNALS
}

\author{
C.N. CAPSALIS, C.P. CHRONOPOULOS, J.G. TIGELIS AND \\ N.K. UZUNOGLU \\ Department of Electrical Engineering, National Technical University of Athens, Athens 10682, Greece
}

(Received October 8, 1990; in final form September 9, 1991)

\begin{abstract}
A theoretical model for the electrical characterization of multi-pin modular daughterboard-to-backplane connectors at high bit rate signals is developed. The fundamental field equations are transformed into a linear system of equations for the currents and voltages at the edges of the pins of the connector.

Efficient formulaes for the calculation of self and mutual inductances and capacitances between the pins which are involved in the linear system of equations are obtained. Using the previous developed theoretical model the connector's performance can be examined in both the frequency and the time domain.

Numerical calculations are performed for three types of existing connectors. Furthermore, they are compared to each other for bit-rates in the range of $100 \mathrm{Mbits} / \mathrm{sec}$ up to $500 \mathrm{Mbits} / \mathrm{sec}$.
\end{abstract}

Key words: Models for connectors, High bit rate connectors, Standard Euro connectors, Teradyne HD +1 connectors, Teradyne HD + 2 connectors

\section{INTRODUCTION}

The growing tendency towards applications involving the propagation of high-bitrate signals has revealed the characteristics of short line elements such as connectors into an important factor in designing high-speed logic devices. In fact, three important constraints in the use of connectors for high speed signals applications must be taken into account ${ }^{1}$.

The first constraint refers to the reflections due to impedance mismatch. These reflections can cause problems in digital circuitry when the delays due to the interconnection distance are significant compared to signal switching times. The connector's impedance is determined by its geometry and configuration (distribution of grounded pins). The impedance mismatch is important not only because it causes undesirable reflections. It can also affect the characteristics of the transmitted waveform. The grade of this influence depends on the signal's rise and fall time and the discontinuity level.

The second constraint is crosstalk between the signal contacts. In open systems such as multi-pin modular daughterboard-to-backplane connectors, where the pins are not shielded from one another, crosstalk is a strong interference source. The absence of electromagnetic isolation between the pins results into capacitive and inductive coupling between them. Two types of crosstalk can be defined, far-end and near-end, depending on the direction they propagate. Near-end crosstalk prop- 
agates on the opposite direction in respect to the transmitted signal, while, far-end crosstalk propagates to the same direction with the transmitted signal. In most connectors near-end crosstalk is more strong than the far-end is. The factors that mainly determine the crosstalk level are signal's switching times, as well, as the connector's geometry (existence of ground planes) and its configuration (grounding percentage).

Finally, the third constraint is self and mutual inductances of the pins used for the signal transmission (hot pins) and of the grounded pins, as they affect the "ground inductance." The geometry of the connector is the most important factor that influences the equivalent inductance of a ground connection.

In this paper the behavior of multi-pin modular daughterboard-to-backplane connectors at high-bit-rate signals is analyzed by means of a theoretical model of the connector's assembly developed using electromagnetic theory principles. Efficient formulaes for the calculation of self and mutual inductances and capacitances between the pins of the connector in respect to the existence or not of ground planes, the connector's configuration and the signal's rise time in respect to the crosstalk level is presented. Furthermore, a comparison of three types of existing connectors, Standard EURO (no ground plane), Teradyne HD + 1 (one ground plane) and Teradyne HD +2 (two ground planes), is made for bit-rates in the range of $100 \mathrm{Mbits} / \mathrm{sec}$ up to $500 \mathrm{Mbits} / \mathrm{sec}$.

The transverse electromagnetic mode assumption is used throughout the following analysis, as the outside of the connector is considered to be metallised.

\section{ANALYTICAL MODEL}

A generic multi-pin connector model consisting of $N$ pins is presented in Fig. 1 .

The two well known equations derived from the coupled transmission lines theory ${ }^{2,3}$

$$
\begin{aligned}
& \mathrm{V}_{\mathrm{m}}-\mathrm{V}_{\mathrm{m}}-\mathrm{R}_{\mathrm{c}} \mathrm{I}_{\mathrm{m}}-\mathrm{j} \omega \sum_{\mathrm{i}=1}^{\mathrm{N}} \mathrm{L}_{\mathrm{mi}} \mathrm{I}_{\mathrm{i}}=0 \quad \mathrm{~m}=1,2, \ldots, \mathrm{N} \\
& \mathrm{I}_{\mathrm{m}}-\mathrm{i}_{\mathrm{m}}-\mathrm{j} \omega \sum_{\mathrm{i}=1}^{\mathrm{N}} \mathrm{C}_{\mathrm{mi}} \mathrm{V}_{\mathrm{i}}=0
\end{aligned}
$$

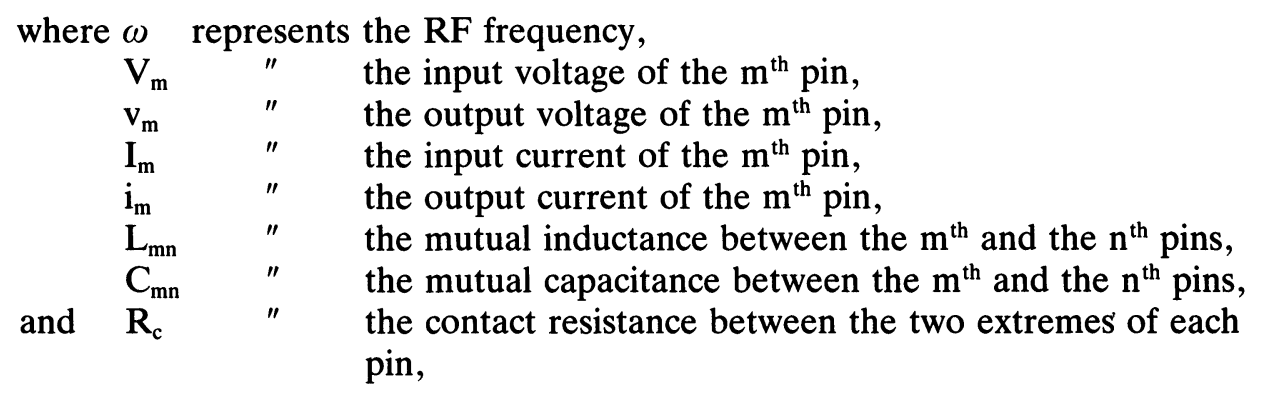

constitute the basis of our theoretical approach. 


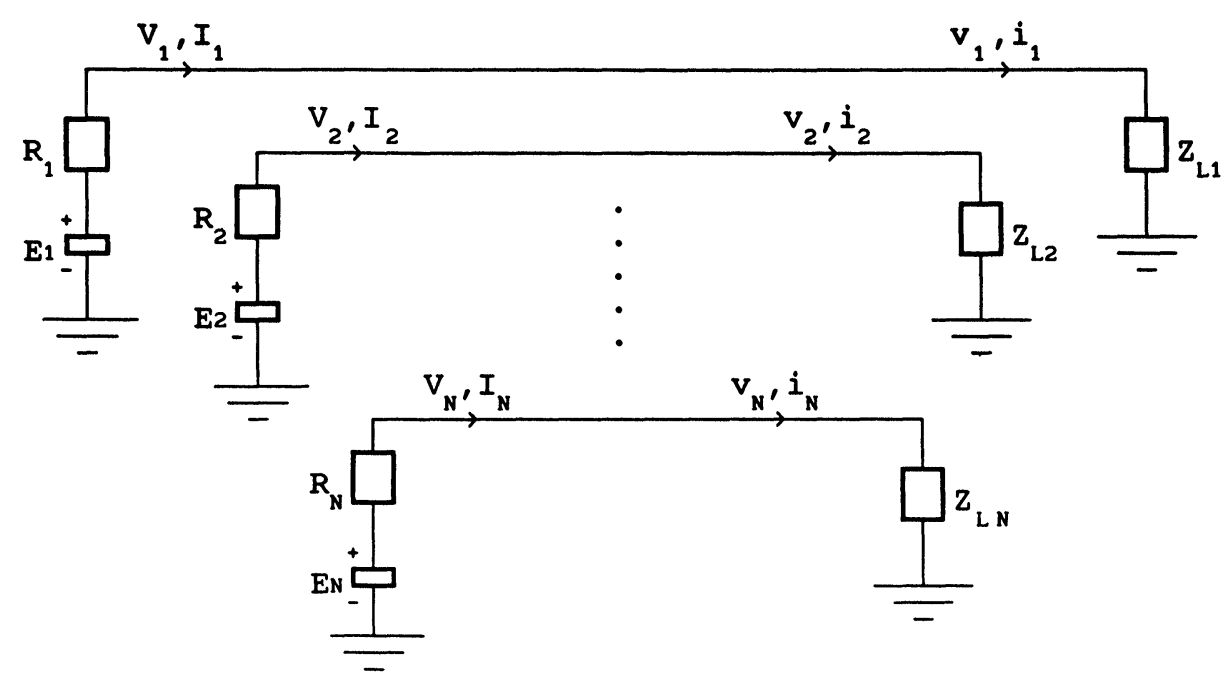

FIGURE 1 Generic multi-pin connector model.

Notice that when $m=n, L_{m n}$ and $C_{m n}$ represent the self inductance and capacitance of the $\mathrm{m}^{\text {th }}$ pin respectively.

The analytical expressions for the $L_{m n}$ and $C_{m n}$ parameters are derived by employing well known electrostatic techniques ${ }^{3,4}$ presented in Appendix A.

Applying the initial conditions for each pin (see Fig. 1), the following equations are obtained:

$\mathrm{V}_{\mathrm{m}}=\mathrm{E}_{\mathrm{m}}-\mathrm{I}_{\mathrm{m}} \mathrm{R}_{\mathrm{m}} \quad \mathrm{m}=1,2, \ldots, \mathrm{N}$

$\mathrm{v}_{\mathrm{m}}=\mathrm{i}_{\mathrm{m}} \mathrm{Z}_{\mathrm{Lm}}$

where $E_{m}$ represents the source voltage of the $m^{\text {th }}$ pin,

$\begin{array}{lll}R_{m} & \text { and } Z_{\mathrm{Lm}} & \text { the source internal resistance of the } \mathrm{m}^{\text {th }} \text { pin, } \\ \text { the load resistance of the } \mathrm{m}^{\text {th }} \text { pin. }\end{array}$

Evidently, the linear system of eqs (1), (2), (3) and (4) describes totally the electrical performance of the multi-pin connector in the frequency domain. Furthermore, by calculating $V_{m}$ and $v_{m}$ we can derive all the information we need about the near-end and far-end crosstalk respectively.

The time domain performance can be described by the system of eqs (1)-(2) if the $\mathrm{j} \omega$ operand is replaced by $\partial / \partial \mathrm{t}$.

\section{NUMERICAL RESULTS}

The time domain performance of three types of existing connectors, Standard EURO (no ground plane), Teradyne HD 1 (one ground plane) and Teradyne $\mathrm{HD}+2$ (two ground planes), is presented. The influence of the existence or not of ground planes in respect mainly to the crosstalk level is evaluated. Furthermore, 
the impact of the connector's configuration (grounded pins percentage) and the signal's switching times into these types of connectors is analyzed.

The following standard grounding configurations are examined:

TABLE I

Grounding pins configurations.

\begin{tabular}{|c|c|c|c|c|c|c|c|}
\hline & $\begin{array}{l}0 \\
12345\end{array}$ & 6789 & $\begin{array}{l}1 \\
012345\end{array}$ & $\begin{array}{r}2 \\
67890\end{array}$ & $\begin{array}{c}3 \\
1234567890\end{array}$ & 1 & 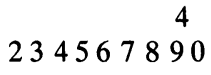 \\
\hline A & ০\#०০০ & $\mathbf{x x x x}$ & ००००\#० & $\mathbf{x x x x x}$ & $\circ \mathbf{x} \circ \mathbf{x} \circ \mathbf{x} \# \mathbf{x} \circ \mathbf{x}$ & $\mathbf{x}$ & ○०\#००\#००০ \\
\hline B & ০০০\#০ & $\mathbf{x x x x}$ & ○ $\bigcirc x \circ \circ$ & $\operatorname{xxxxx}$ & $\circ x \# x \circ x \circ x \circ x$ & ० & $x \circ x \circ 0 x \# x$ \\
\hline $\mathrm{C}$ & ○\#००० & $\mathbf{x x x x}$ & $x \circ 00 \# \circ$ & $\mathbf{x x x x x}$ & $\circ x \circ x \circ x \circ x \# x$ & $\mathbf{x}$ & $\circ x \circ x \# x \circ x \circ$ \\
\hline \multirow[t]{2}{*}{ D } & ০০০\#০ & $\mathrm{xxxx}$ & ○\#०००० & $\operatorname{xxxxx}$ & $x \# x \circ x \circ x \circ x \circ$ & $\mathbf{x}$ & ০\#००००\#०০ \\
\hline & $100 \%$ & $* *$ & $92 \%$ & $* *$ & $75 \%$ & $* *$ & $50 \%$ \\
\hline
\end{tabular}

$\mathbf{x}=$ grounded pin

$\mathrm{O}=$ active pin (hot pin)

\# = passive pin

A trapezoidal pulse of width $T_{w}$ and rise and fall time $T_{r}=T_{w} / 3$ and amplitude $1 \mathrm{~V}$ is considered as the source voltage. The source internal resistance and load resistance are considered to be $75 \Omega$.

The time domain performance is derived by employing the inverse Fourrier transform ${ }^{5}$ into the system of eqs (1)-(4).

The Figs. 2 and 3 typical voltage pulses in hot (output voltage) and passive pins (near-end crosstalk) are presented respectively. The effects of the impedance mismatch are apparent in these typical pulses. The degradation of the pulse due to the reflections varies strongly with the type and the configuration of the connector and the singal's rise time.

In Fig. 4 the variation of the mean value of near-end and far-end crosstalk for

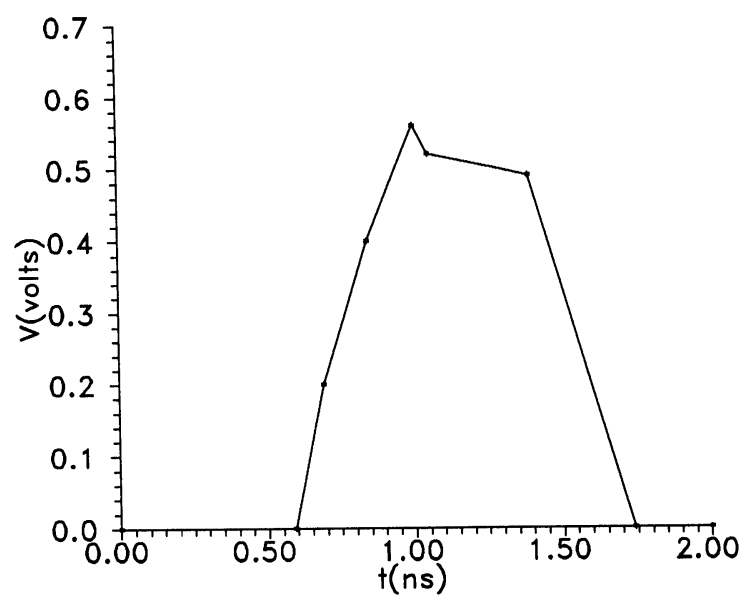

FIGURE 2 Typical output voltage pulse of a hot pin (active). 


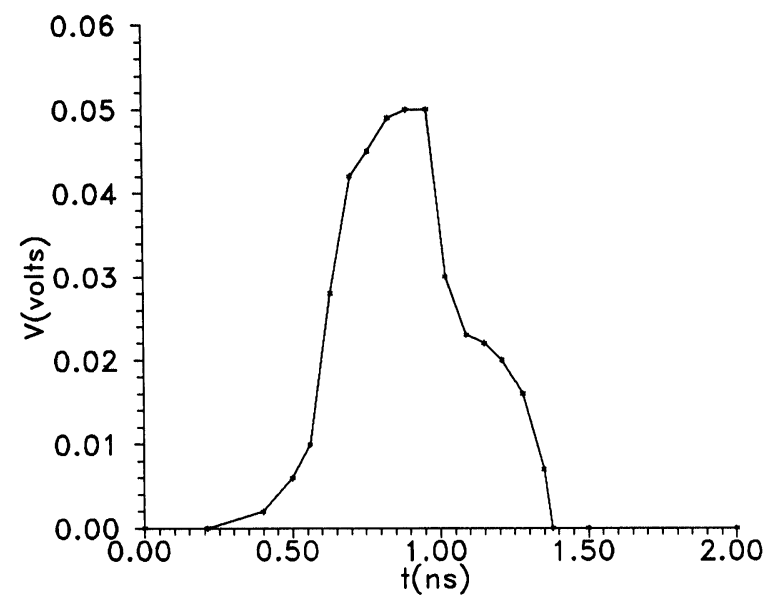

FIGURE 3 Typical voltage pulse of a passive pin (near-end crosstalk).

one active pin in respect to the grounding configuration is presented for the above mentioned types of connectors. The distribution of crosstalk level among the pins depends mainly to the distance between passive and hot pins.

Finally, in Fig. 5 the influence of the signal's rise time in the crosstalk level (near-end and far-end) is presented for the $\mathrm{HD}+2$ connector with $100 \%$ configuration.

The theoretical results were verified against experimental data obtained by a test setup. The test setup consists of a daughterboard and a backpanel connected to each other through the connector under test. The theoretical results were found to be quite accurate compared to the experimental data. In Fig. 6 the comparison

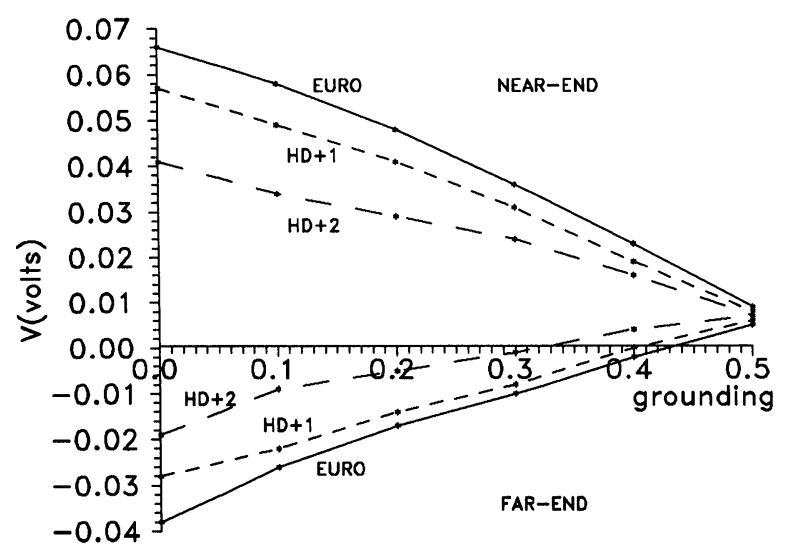

FIGURE 4 Variation of the mean value of near-end and far-end crosstalk for one active pin for Standard EURO, Teradyne $\mathrm{HD}+1$ and Teradyne $\mathrm{HD}+2$ connectors in respect to the grounding configuration. 


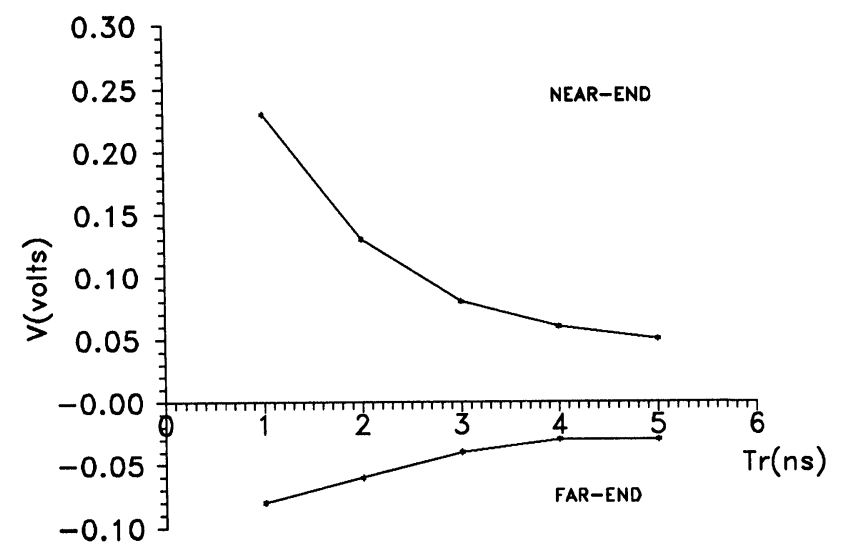

FIGURE 5 Variation of the mean value of near-end and far-end crosstalk for one active pin for the Teradyne HD +2 connector ( $100 \%$ configuration) with the signal's rise time.

of the theoretical and the experimental mean value of near-end and far-end crosstalk in respect to the grounding configuration is presented for the EURO connector.

\section{CONCLUSIONS}

A generic analytical model for the electrical characterization of multi-pin modular daughterboard-to-backplane connectors at high bit-rate signals is presented.

The crosstalk between the signal pins reveals as the major constraint for signal's transmission at bit-rates in the range of $100 \mathrm{Mbits} / \mathrm{sec}$ up to $500 \mathrm{Mbits} / \mathrm{sec}$.

The existence of one at least ground plane, as well as, a $50 \%$ grounding configuration may be required in order to reduce the crosstalk level into acceptable

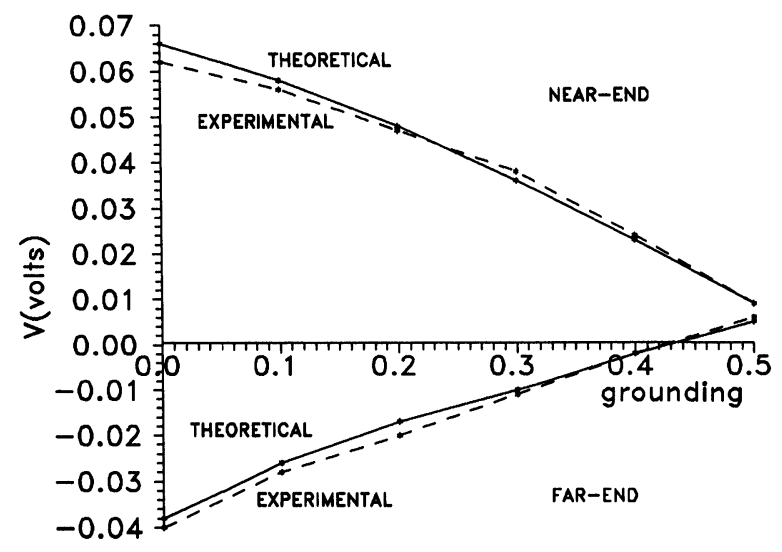

FIGURE 6 Comparison of the theoretical and the experimental mean value of near-end and far-end crosstalk for one active pin for the EURO connector in respect to the grounding configuration. 
limits for signal's transmission at bit-rates in the range of $100 \mathrm{Mbits} / \mathrm{sec}$ up to 500 Mbits/sec.

\section{REFERENCES}

1. W.M. Gailus and J.A. Siemon, "Characterization of Connector Performance for High-Speed Signal Applications," VLSI Design, March 1985.

2. R.E. Collin, Foundations for Microwave Engineering, McGraw-Hill, New York, 1986.

3. D.S. Jones, The Theory of Electromagnetism, Pergamon Press, Oxford, 1964.

4. R. Mittra and S.W. Lee, Analytical Techniques in the Theory of Guided Waves, Macmillan, New York, 1971.

5. M. Abramowitz and I.A. Stegun, Handbook of Mathematical Functions, Dover Publications, New York, 1970.

\section{APPENDIX A}

The analytical expressions for the calculation of the self and mutual inductances and capacitances between the pins for three cases of connectors in respect to the existance or not of ground planes are presented.

\section{Connectors without Ground Plane}

$$
\begin{aligned}
& \mathrm{L}_{\mathrm{mm}}=\frac{\mu_{0} l}{2 \pi}\left(\ln \frac{2 \mathrm{l}}{\mathrm{a}}-\frac{3}{4}\right) \\
& \mathrm{L}_{\mathrm{mn}}=\frac{\mu_{0} l}{4 \pi} \ln \left\{\frac{\left(\mathrm{x}_{\mathrm{n}}-\mathrm{x}_{\mathrm{m}}\right)^{2}+\left(\mathrm{y}_{\mathrm{n}}+\mathrm{y}_{\mathrm{m}}\right)^{2}}{\mathrm{a}^{2}}\right\} \\
& \mathrm{C}_{\mathrm{mm}}=2 \pi \varepsilon_{0} 1 /\left(\ln \frac{21}{\mathrm{a}}-\frac{3}{4}\right) \\
& \mathrm{C}_{\mathrm{mn}}=4 \pi \varepsilon_{0} 1 / \ln \left\{\frac{\left(\mathrm{x}_{\mathrm{n}}-\mathrm{x}_{\mathrm{m}}\right)^{2}+\left(\mathrm{y}_{\mathrm{n}}-\mathrm{y}_{\mathrm{m}}\right)^{2}}{\mathrm{a}^{2}}\right\}
\end{aligned}
$$

where $x_{n}, y_{n}$ represent the coordinates of the $n^{\text {th }}$ pin,

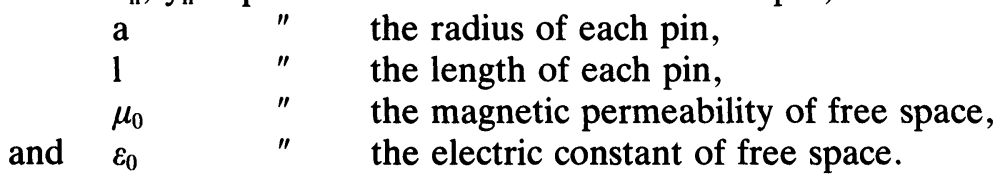

\section{Connectors with One Ground Plane}

$$
\begin{aligned}
& \mathrm{L}_{\mathrm{mm}}=\frac{\mu_{0} \mathrm{l}}{2 \pi} \ln \frac{2 \mathrm{y}_{\mathrm{m}}}{\mathrm{a}} \\
& \mathrm{L}_{\mathrm{mn}}=\frac{\mu_{0} \mathrm{l}}{4 \pi} \ln \left\{\frac{\left(\mathrm{x}_{\mathrm{n}}-\mathrm{x}_{\mathrm{m}}\right)^{2}+\left(\mathrm{y}_{\mathrm{n}}+\mathrm{y}_{\mathrm{m}}\right)^{2}}{\left(\mathrm{x}_{\mathrm{n}}-\mathrm{x}_{\mathrm{m}}\right)^{2}+\left(\mathrm{y}_{\mathrm{n}}+\mathrm{y}_{\mathrm{m}}\right)^{2}}\right\}
\end{aligned}
$$


$\mathrm{C}_{\mathrm{mm}}=2 \pi \varepsilon_{0} 1 / \ln \frac{2 \mathrm{y}_{\mathrm{m}}}{\mathrm{a}}$
$\mathrm{C}_{\mathrm{mn}}=4 \pi \varepsilon_{0} 1 / \ln \left\{\frac{\left(\mathrm{x}_{\mathrm{n}}-\mathrm{x}_{\mathrm{m}}\right)^{2}+\left(\mathrm{y}_{\mathrm{n}}+\mathrm{y}_{\mathrm{m}}\right)^{2}}{\left(\mathrm{x}_{\mathrm{n}}-\mathrm{x}_{\mathrm{m}}\right)^{2}+\left(\mathrm{y}_{\mathrm{n}}-\mathrm{y}_{\mathrm{m}}\right)^{2}}\right\}$

III. Connectors with Two Ground Planes

$$
\begin{aligned}
& \mathrm{L}_{\mathrm{mm}}=\frac{\mu_{0} \mathrm{l}}{4 \pi}\left\{\ln \frac{2 \mathrm{y}_{\mathrm{m}}}{\mathrm{a}}+\sum_{\mathrm{k}=1}^{\infty} \ln \left(\frac{2 \mathrm{kh}+\mathrm{y}_{\mathrm{m}}}{2 \mathrm{kh}-\mathrm{y}_{\mathrm{m}}}\right)\right\} \\
& \mathrm{L}_{\mathrm{mn}}=\frac{\mu_{0} 1}{4 \pi}\left\{\ln \frac{\left(\mathrm{x}_{\mathrm{n}}-\mathrm{x}_{\mathrm{m}}\right)^{2}+\left(\mathrm{y}_{\mathrm{n}}+\mathrm{y}_{\mathrm{m}}\right)^{2}}{\left(\mathrm{x}_{\mathrm{n}}-\mathrm{x}_{\mathrm{m}}\right)^{2}+\left(\mathrm{y}_{\mathrm{n}}-\mathrm{y}_{\mathrm{m}}\right)^{2}}+\sum_{\mathrm{k}=1}^{\infty}\right. \\
& \left.\times\left\{\ln \frac{\left(x_{n}-x_{m}\right)^{2}+\left(2 k h+y_{n}+y_{m}\right)^{2}}{\left(x_{n}-x_{m}\right)^{2}+\left(2 k h+y_{n}-y_{m}\right)^{2}}-\ln \frac{\left(x_{n}-x_{m}\right)^{2}+\left(2 k h-y_{n}+y_{m}\right)^{2}}{\left(x_{n}-x_{m}\right)^{2}+\left(2 k h-y_{n}-y_{m}\right)^{2}}\right\}\right\} \\
& \mathrm{C}_{\mathrm{mm}}=2 \pi \varepsilon_{0} \mathrm{l} /\left\{\ln \frac{2 \mathrm{y}_{\mathrm{m}}}{\mathrm{a}}+\sum_{\mathrm{k}=1}^{\infty} \ln \left(\frac{2 \mathrm{kh}+\mathrm{y}_{\mathrm{m}}}{2 \mathrm{kh}-\mathrm{y}_{\mathrm{m}}}\right)\right\} \\
& C_{m n}=4 \pi \varepsilon_{0} l /\left\{\ln \frac{\left(x_{n}-x_{m}\right)^{2}+\left(y_{n}+y_{m}\right)^{2}}{\left(x_{n}-x_{m}\right)^{2}+\left(y_{n}-y_{m}\right)^{2}}+\sum_{k=1}^{\infty}\right. \\
& \left.\times\left\{\ln \frac{\left(x_{n}-x_{m}\right)^{2}+\left(2 k h+y_{n}+y_{m}\right)^{2}}{\left(x_{n}-x_{m}\right)^{2}+\left(2 k h+y_{n}-y_{m}\right)^{2}}-\ln \frac{\left(x_{n}-x_{m}\right)^{2}+\left(2 k h-y_{n}+y_{m}\right)^{2}}{\left(x_{n}-x_{m}\right)^{2}+\left(2 k h-y_{n}-y_{m}\right)^{2}}\right\}\right\}
\end{aligned}
$$

where $\mathrm{h}$ represents the distance between the two ground planes. 

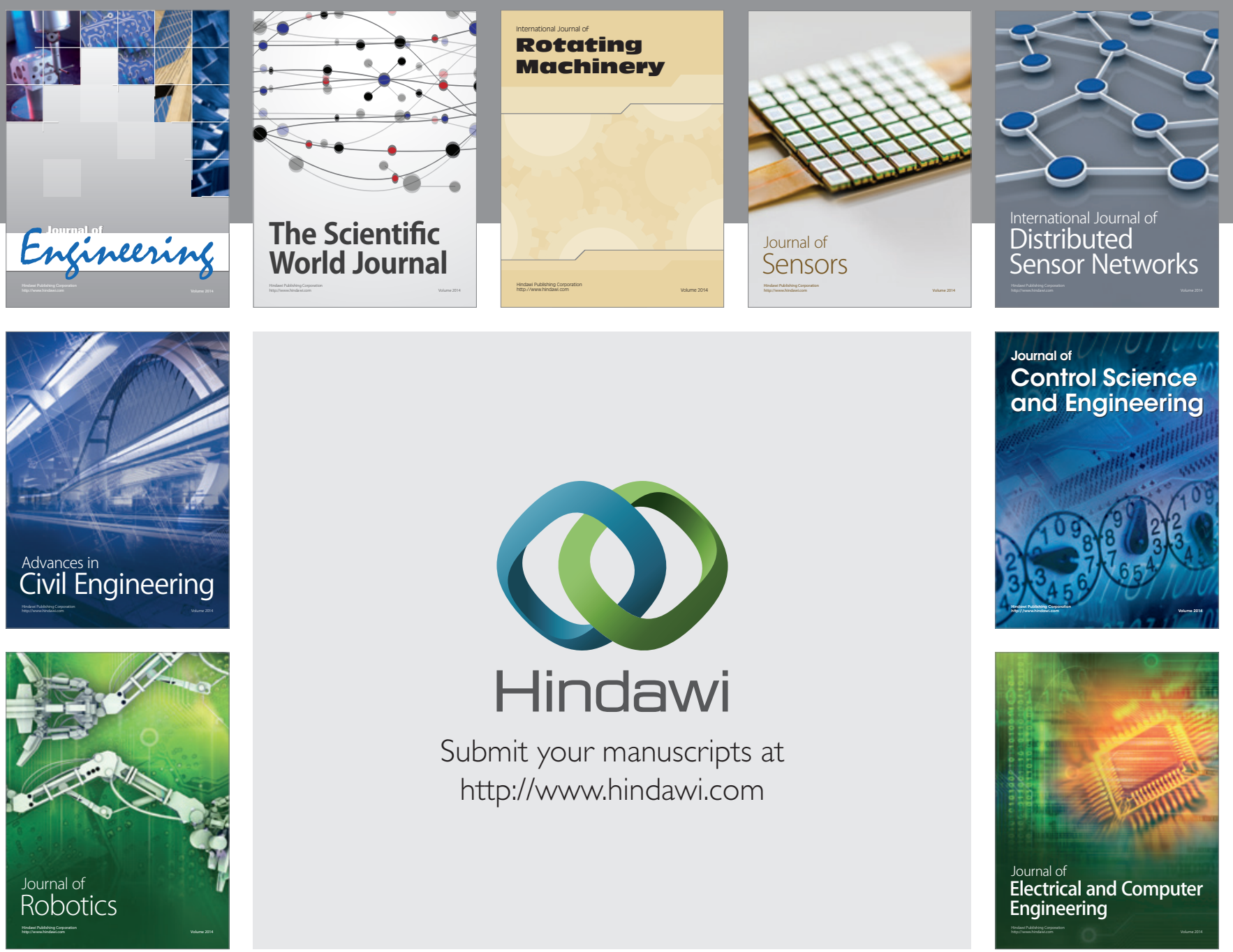

Submit your manuscripts at

http://www.hindawi.com
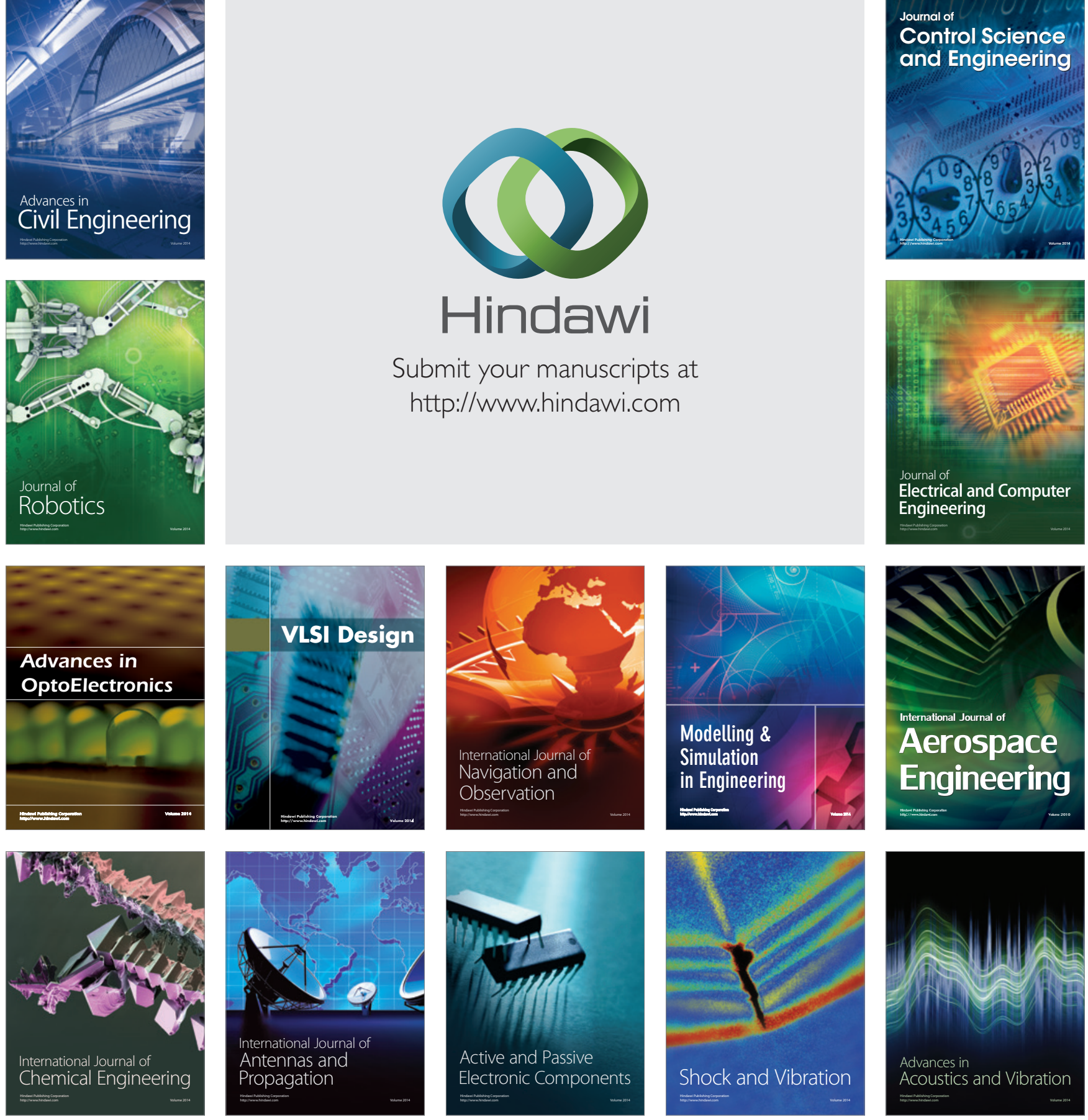